\title{
Study of human and environmental impacts on the growth of flora of Khanozai-Muslimbagh highway in Balochistan
}

\author{
Muhammad Kamran Panizai* and Saeed Ur Rehman Kakar \\ Department of Botany, University of Balochistan, Quetta-Pakistan \\ *Corresponding author's email: kamranpanizai@gmail.com
}

Citation

Muhammad Kamran Panizai and Saeed Ur Rehman Kakar. Study of human and environmental impacts on the growth of flora of Khanozai-Muslimbagh highway in Balochistan. Pure and Applied Biology. Vol. 8, Issue 2, pp1348-1358. http://dx.doi.org/10.19045/bspab.2019.80076

\begin{tabular}{llll}
\hline \hline Received: 27/02/2019 & Revised: 23/04/2019 & Accepted: 26/04/2019 & Online First: 30/04/2019 \\
\hline
\end{tabular}

\section{Abstract}

The area between Khanozai and Muslimbagh towns have variation in altitude, topography and vegetation but no study of the area has been carried out so far. This study was conducted to find out the impact of human activities (dust, grazing, urbanization and defecation) and environmental factors (underground water table, altitude and temperature) on the growth of wild flora. Initiating from vegetative profiling, 20 stands were taken at different points based on which 3 most dominant species of the area, Artemisia longifolia (Vernacular name: Tharkha), Peganum hermala (Vernacular name: spaanda) and Sophora mollis (Vernacular Name: Ghuraiza) were identified. For analyzing the impact of human factors, samples were taken near and away from chromite crushing plants, routes of herds, settlements and open defecation points in towns for dust, grazing, urbanization and defecation respectively. Findings revealed dust to be most lethal for plants. Dust from chromite refineries in the outskirts of Muslimbagh town causes thick layers of soil on surrounding plants and reduces the plant growth by 50\%, at average. Smoke of automobiles was found to be least effective growth but has major role on plant distribution along the roadside. Samples taken from herds' route, defecation places and urban areas showed higher growth values due to lesser competition for resources among the plants. Moisture, sunlight and altitude found to pose mix effect on growth parameters and plants. Detailed phytosociological study of the area, transferring chromite plants away from human settlements and plantation of trees along the roadside are the steps recommended after the study.

Keywords: Artemisia longifolia, Khanozai, Muslim Bagh, Peganum hermala, Sophora mollis

\section{Introduction}

Balochistan is the largest province of Pakistan and located in south west of it. It covers about $43 \%$ of country's total area having the population of around 6 million, only $4 \%$ of country's population. Geologically, Balochistan is located in the eastern part of Iranian plateau between $250^{\circ}$ to $320^{\mathrm{O}} \mathrm{N}$ latitude and $600^{\mathrm{O}}$ to $720^{\mathrm{O}} \mathrm{E}$ longitude. In province, $96 \%$ of the land resource is uncultivated due to scarcity of water. $40 \%$ of cultivated land is irrigated while $60 \%$ is rain-fed. $60 \%$ of the land 
resource of province is comprised of rangelands [1].

Khanozai is situated in Pishin district of Baluchistan, Pakistan, its geographical coordinates are $30^{\circ} 25^{\prime} 45^{\prime \prime}$ North, 66 $33^{\prime} 19^{\prime \prime}$ East on Quetta Zhob National Highway at a distance of $72 \mathrm{KM}$ from Quetta, the provincial capital of Balochistan [2]. Muslim Bagh is a town of Qilla Saifullah District situated on the same route at a distance off 50 KM from Khanozai town [2]. The $50 \mathrm{KM}$ national highway between these two towns is the part of well paved and developed interprovincial route which connects Balochistan with Punjab and Khyber Pakhtunkhwa. This target segment of highway is the part of proposed western route of China Pakistan Economic Corridor (CPEC).

In late 90's, this region went through a severe drought which extended for a period of more than 5 years. Although Balochistan has experienced several droughts but the drought of 1997-2002 was the most prolonged in many years [3]. According to the Ministry of Finance, this famine caused a loss of PKR 25 billion to the national treasury in the year 2000-2002 [3].

The floristic composition of Khanozai and Muslim Bagh, generally and the highway between them, specifically have not been identified and reported yet. The present work was initiated with the identification of plants and developing the floristic composition of highway between both towns through plant quadrate method. Prior current work, no record was found regarding reporting of similar work in the same area. Thus, current work was first of its kind in terms of area as well as topic.

\section{Materials and methods}

Based on the nature of current study, it was essential to have the floristic composition of the area. After searching through all available sources, it was found that floristic composition of area was not reported till the date of the inception of this research work. Thus, the work was initiated with the description of flora of area through line intercept method by Canfield [4]. Another purpose of the vegetational study was to find out 3 most dominant species of the study are, which were then considered for impact study i.e. the main purpose of this research work.

In this regard, a total of 20 stands were taken in different parts of the target area, selected on the base of variance in altitude, land structure, distance from highway etc. In each stand, 100 feet long line was laid and species and covers of the intercepting plants were noted. The nomenclature followed for naming these plants was that of Nasir et al. [5]. A quantitative floristic description of the flora of all these 20 stands was generated in which three most dominant species were identified. These three dominant species were then taken for qualitative floristic description and environmental study. Quantitative description yielded the plant species which are present in the area while qualitative description helped in identifying the difference between traits due to environmental and human factors.

\section{Soil analysis}

The Soils analysis of the area was also carried out by taking soil sample from 6 different areas by the method proposed by Cindy Fake [6]. Polyethylene bags were used for containing the soil. Findings of the soil analysis are elaborated in (Table 1).

\section{Studying human and environmental impacts on flora}

These three species were then collected for different locations to study the impact of respective factor on its growth. The traits of selected plant species were made on the basis of several human and ecological factors which are summarized as under: 
Table 1. Soil characteristics of the communities

\begin{tabular}{|c|c|c|c|c|c|c|c|c|c|}
\hline $\begin{array}{l}\text { S. } \\
\text { No. }\end{array}$ & Name of Communities & $\begin{array}{l}\text { Sand } \\
(\%)\end{array}$ & $\begin{array}{l}\text { Silt } \\
(\%)\end{array}$ & $\begin{array}{l}\text { Clay } \\
(\%)\end{array}$ & $\begin{array}{l}\text { Textural } \\
\text { Class }\end{array}$ & $\begin{array}{c}\text { Organic } \\
\text { Matter } \\
(\%)\end{array}$ & $\begin{array}{c}\text { MWHC } \\
(\%)\end{array}$ & $\begin{array}{c}\mathrm{CaCo3} \\
(\%)\end{array}$ & pH \\
\hline 1 & $\begin{array}{c}\text { Artemisia longifolia - } \\
\text { Cozinia community }\end{array}$ & 70.40 & 16.50 & 13.06 & S.L. & 1.97 & 36.63 & 20.61 & 7.30 \\
\hline 2 & $\begin{array}{l}\text { Cozinia - Artemisia } \\
\text { longifolia - Peganum } \\
\text { harmala community }\end{array}$ & 70.40 & 13.80 & 15.73 & S.L. & 2.50 & 38.52 & 17.32 & 7.10 \\
\hline 3 & $\begin{array}{c}\text { Artemisia longifolia - } \\
\text { Hertia intermedia - } \\
\text { Sophora mollus } \\
\text { community } \\
\end{array}$ & 76.40 & 07.73 & 15.86 & S.L. & 1.20 & 34.69 & 25.84 & 8.09 \\
\hline 4 & $\begin{array}{l}\text { Pervoskia artplicifolia } \\
\text { - Artemisia longifolia } \\
\text { community }\end{array}$ & 58.30 & 14.80 & 26.80 & S.C.L. & 2.50 & 40.71 & 17.50 & 8.04 \\
\hline 5 & $\begin{array}{l}\text { Alhagi maurorum - } \\
\text { Peganum harmala - } \\
\text { Cozinia community }\end{array}$ & 62.40 & 14.26 & 23.33 & S.C.L. & 1.99 & 41.87 & 20.82 & 7.60 \\
\hline 6 & $\begin{array}{l}\text { Astragalus stocksii - } \\
\text { Artemisia longifolia- } \\
\text { Sophora mollis } \\
\text { Community }\end{array}$ & 75.20 & 06.80 & 18.00 & S.L. & 1.30 & 33.96 & 25.64 & 7.94 \\
\hline
\end{tabular}

\section{Studying Human and environmental impacts on flora}

These three species were then collected for different locations to study the impact of respective factor on its growth. The traits of selected plant species were made on the basis of several human and ecological factors which are summarized as under:

\section{Human Activities focused in the study Smoke particles}

Smoke is a collection of airborne solid and liquid particulates and gas es Hurley et al. [7]. For determining the smoke particles on the plants, two samples were taken from each location. One by the road side and other about 500 meters away from the road. Sampling was repeated 3 times from different towns. Generally, plant samples taken from roadside were expected to be having more smoke particles secreted by automobiles on road as compared to samples taken from far place on the same location. The growth and other physical parameters were calculated in the laboratory and interpreted among the samples having more smoke particles and those away from road.

\section{Grazing}

When the shepherd gets herds for grazing, they follow some specific path from years. Although herds deviate a little from the path for grazing but generally they don't leave that specific path. Two samples of each plant were taken for determining the effect of grazing. One sample from the path of herds within 10 meters and other in a rangeland away from the path. The growth and other physical parameters of both the samples were calculated in the laboratory and interpreted with each other.

Urbanization:

In this case, again two samples were taken of each plant species. One from densely populated area and other from open rangeland. Sampling was repeated in three different urban settlements. The growth and other physical parameters were calculated in the laboratory and interpreted with each other. 


\section{Human defecation}

In market areas of Khanozai and Muslimbagh towns, there are some specific places where the shopkeepers and visitors defecate in day time. Plants found in these places must be affected by faeces and urination. To determine this impact, samples of all three species were taken from these places and were analyzed and interpreted with the samples taken from areas away from human defecation.

\section{Dust particles}

The roads of the areas are mostly paved and thus no major dust can be observed from roads. However, there are some chromite refining plants in the suburbs of Muslimbagh town which releases bulk of dust throughout the day. This dust not only affect the human settlements in the surroundings but also have visible effect on the flora as well. Plant samples near and away from these refining plants were taken, analyzed and construed accordingly. Controlled samples were taken about 500 meters away from the experimental ones.

\section{Environmental factor focused} Moisture content

The samples of selected plants taken from the premises of orchards contain more moisture than that of taken from open plains and valleys. In this research, plant samples were taken from both the locations to find out the effect of moisture contents on the growth of plants.

\section{Temperature/sunlight}

The south faced part of a hill generally gets huge amount of direct sunlight than the north opened part of the hills. In local language, these are called "Pithawa" and "Sorai". Getting direct sunlight eventually affect the average temperature of both the places. The samples of all three plants were taken from such two different places to find either plants grow better in "Pithawa" or in "Sorai."

\section{Altitude}

The altitude of towns situated on Khanozai Muslibagh highway also varies to some extent from each other. Kan Mehterzai stands on top with altitude of 2,250 meter $(7,469$ Feet) while other towns are lying on comparatively low altitude including Khanozai Town which have an altitude of 1,950 meters (6,378 feet). Samples from Khanozai and Kan Mehterzai towns were taken, having 300 Meters (984 feet) difference in altitudes, keeping other factors constant, so that the effect of altitude may be find out.

\section{Growth Parameters calculated}

\section{Leaf area}

The leaf area plays an important role in plant growth analysis and photosynthesis [8]. Although there are several methods used globally for the measurement of leaf area, however, in current study, leaf area was calculated by graphical method. In each plant studied, leaf was plucked from the lower stem of each plant.

\section{Plant height}

Plant height of selected samples was simply calculated by measuring tape.

\section{Number of leaves and branches}

The number of leaves and branches were separately counted for each of the samples and were then interpreted.

\section{Results and discussion}

\section{Effect of smoke particles on plant growth}

It was yielded in the current study that smoke emitted by automobiles did not imparted any significant impact on different attributes of plant growth (Figure 1) as reported by Hoang et.al, (2011) who also not find any significant effect of smoke. In this study, however, lesser plant height and lesser number of leaflets were observed in samples taken from roadside. These findings are in line with [911] who also reported likewise.

The distribution of plants also differs on roadside and away from roads as artemisia had maximum presence along the road while 
Sophora mollis was lesser in plots taken from roadside, showing resistance to smoke emitted by automobiles in artemisia more than Peganum and sophora species. The results are in contradiction with Bhatti and Iqbal [12] who found that Leaf area and dry weight were significantly reduced due to automobile smoke in most of the plants they studied.
Yanguang and Liu (2018) found in their work that highways affect the natural environment of plants and proposed methods to protect plant slopes during the development work. Munyati, [13] examined the effect of proximity to roads on soil and grass and found that the distribution of grasses varied on roadside and away from the road.

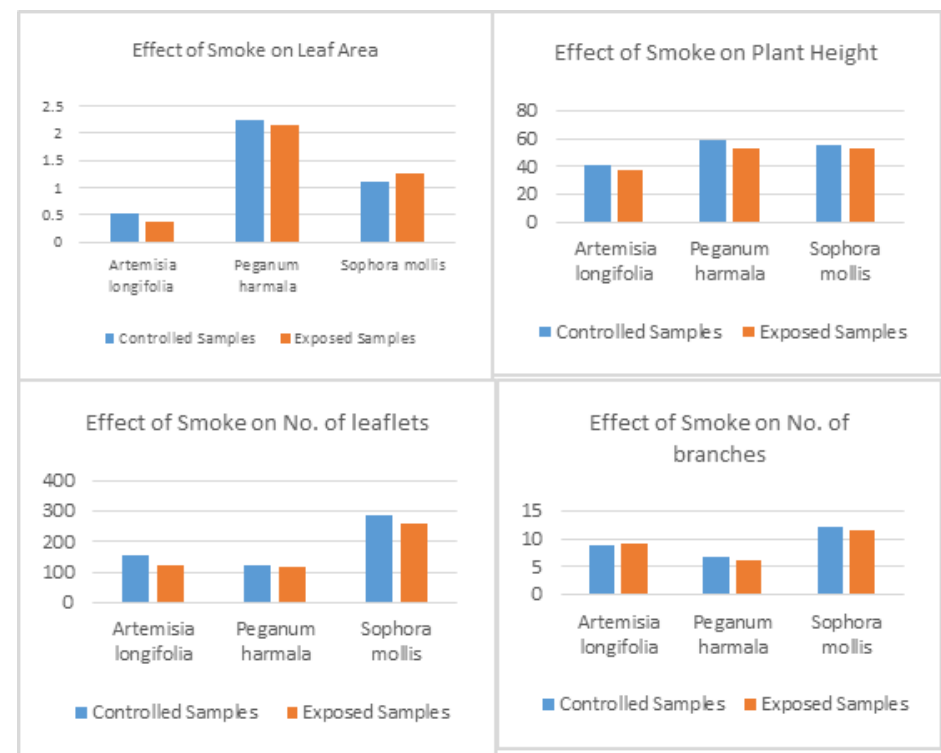

Figure 1. Graphs 1(a), 1(b), 1(c) and 1(d) with graphical presentation of effect of smoke on different growth parameters of plants

\section{Effect of grazing on plant growth}

The results of all samples of selected plants showed that grazing does not impart any significant impact on plant growth (Figure 2). Rather, it affects the plant density and distribution within a community and sometimes it causes changes in plant communities by eradicating or introducing plant species $\mathrm{Na}$ et al. [14]. In current study, it was observed that the plant height of plant samples taken from herd routes were comparatively lesser then the controlled samples. However, at the same time, leaf area, plant height and number of leaflets showed higher tendency in exposed samples. The reason of higher values of leaf area, plant height and number of leaflets might be due to lesser competition among the plants left from sheeps and goats. Lesser the plant density, higher will be the plant height and leaf area [15].

Effect of urban habitat on plant growth parameters

Current study revealed that the plant samples collected from urban settlements showed higher growth tendencies as compared to samples taken from outskirts of towns, with least human interference. In samples of all three of the species collected from town areas, leaf area, plant height, Number of leaves and branches were recorded higher (Figure 3).

In urban area, there is negligible grazing and thus lesser plants found. The competition for 
available resources is not tough and this leads to higher values of growth parameters. These findings second the result of Craine and Dybzinski [15] that when there is lower competition for resources among the plants, the plants grow better. Similar results have been given by Meletiou-Christou et al. [16].

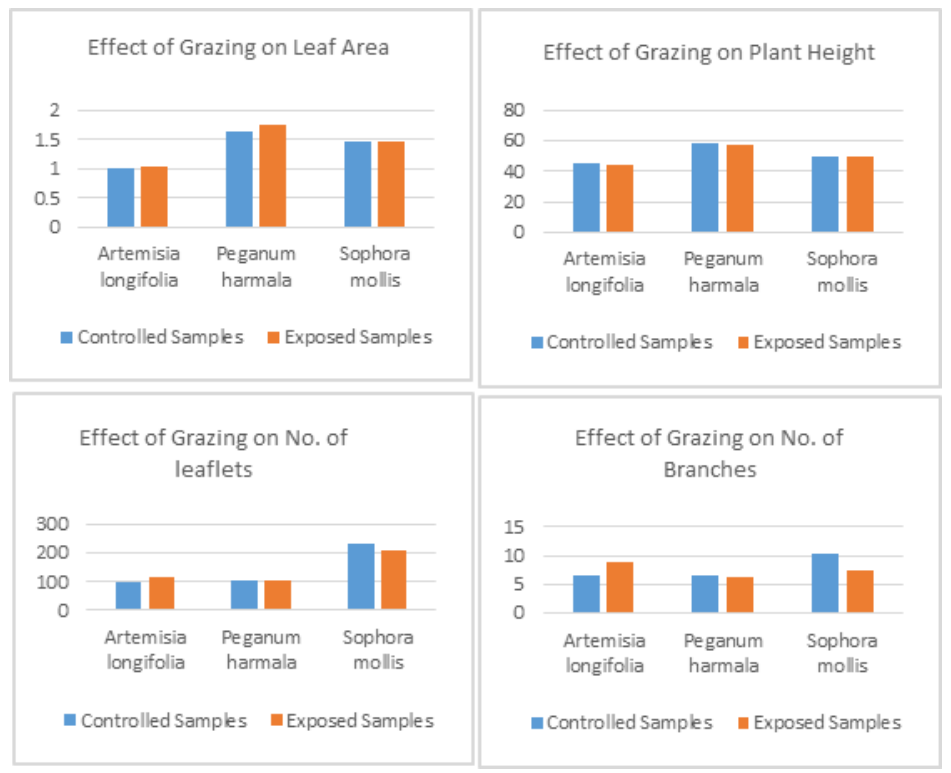

Figure 2. Graphs 2(a), 2(b), 2(c) and 2(d) with Graphical presentation of effect of grazing on different growth parameters of plants

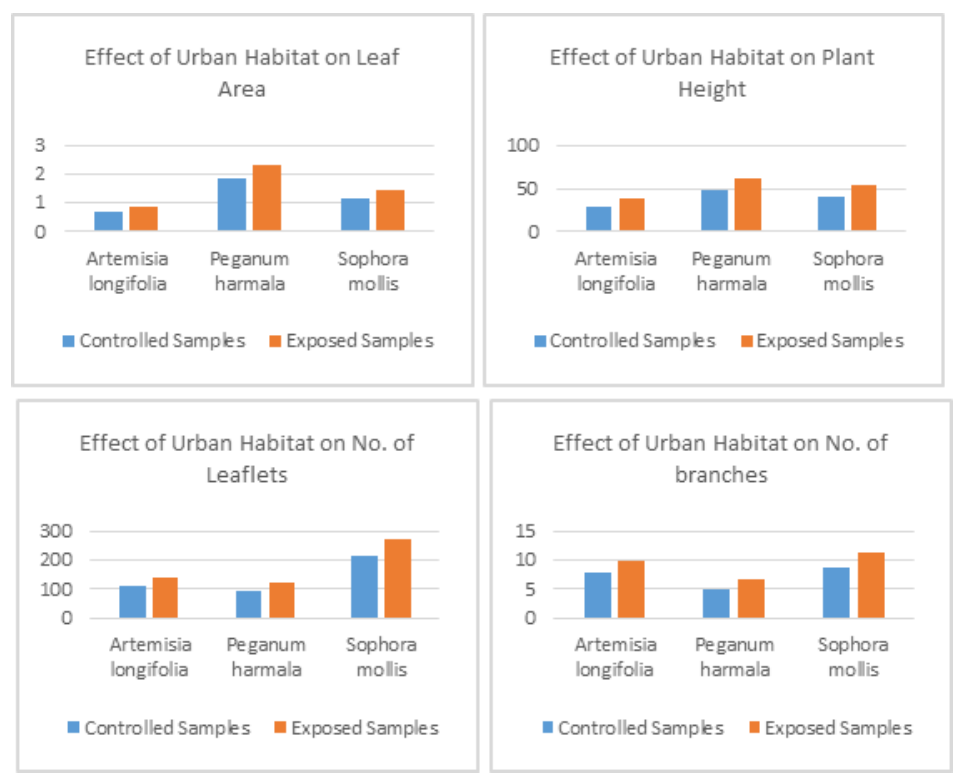

Figure 3. Graphs 3(a), 3(b), 3(c) and 3(d) with Graphical presentation of effect of urban habitat on different growth parameters of plants 
Effect of human defecation on plant growth parameters

The samples of plants taken from defecation points showed declined growth tendency. Leaf area, plant height and number of leaflets of all plants was negatively influenced by human defecation found openly. However, Number of branched was found to be increased under the effect of human faeces. In sophora mollis, the number of leaflets is also enhanced in samples from defecation points (Figure 4).

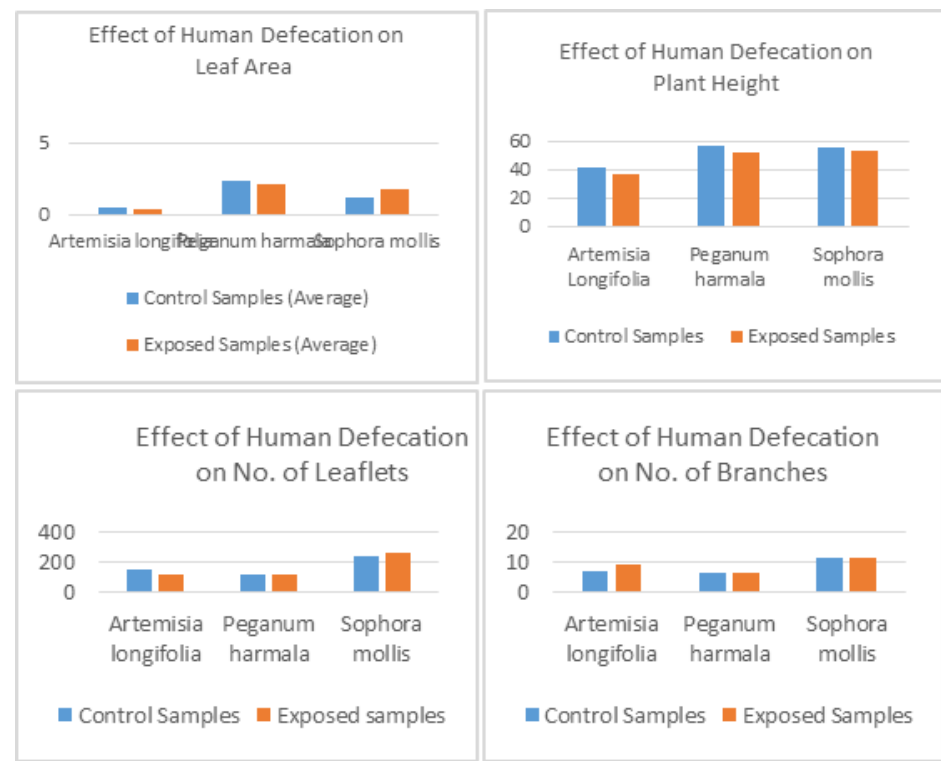

Figure 4. Graphs 4(a), 4(b), 4(c) and 4(d) with graphical presentation of effect of human defecation on different growth parameters of plants

\section{Effect of dust particles on plant growth} parameters

Dust emitting from chromite refining plants imparted the worst effect on growth parameters of all collected samples. An average of $38 \%, 46 \%, 61 \%$ and $57 \%$ decline were observed in leaf area, plant height, Number of leaflets and number of branches of all three plants exposed to dust (Figure 5). These findings are somewhat contrast with Iqbal and Shafiq [17] while in accordance with the findings of Tripathy et al. [18] with minor difference. "The human impact on biological diversity" is an analysis issued by EMBO reports which also states that human impact on plants is remarkably negative.

Effect of moisture on plant growth parameters

Effect of moisture on plant growth parameters was found to be non-uniform but significant in current study. In artemisia samples taken in moisty places, leaf area, plant height and number of branches were lesser while number of leaflets were more than similar samples collected far from orchards. On other hand, in Peganum harmala and Sopphora mollis all growth parameters are showing negative growth (Figure 6).

Razmjoo et al. [19] reported accordingly saying drought (Less moisture) caused a significant reduction in plant height, the number of branches and flowers, peduncle length, head diameter, fresh and dry flower weight and essential oil content. Similar findings have been reported by Ahmad and Kanwar [20] while working on Effect of Different Moisture Stress Levels on Corn Growth. 


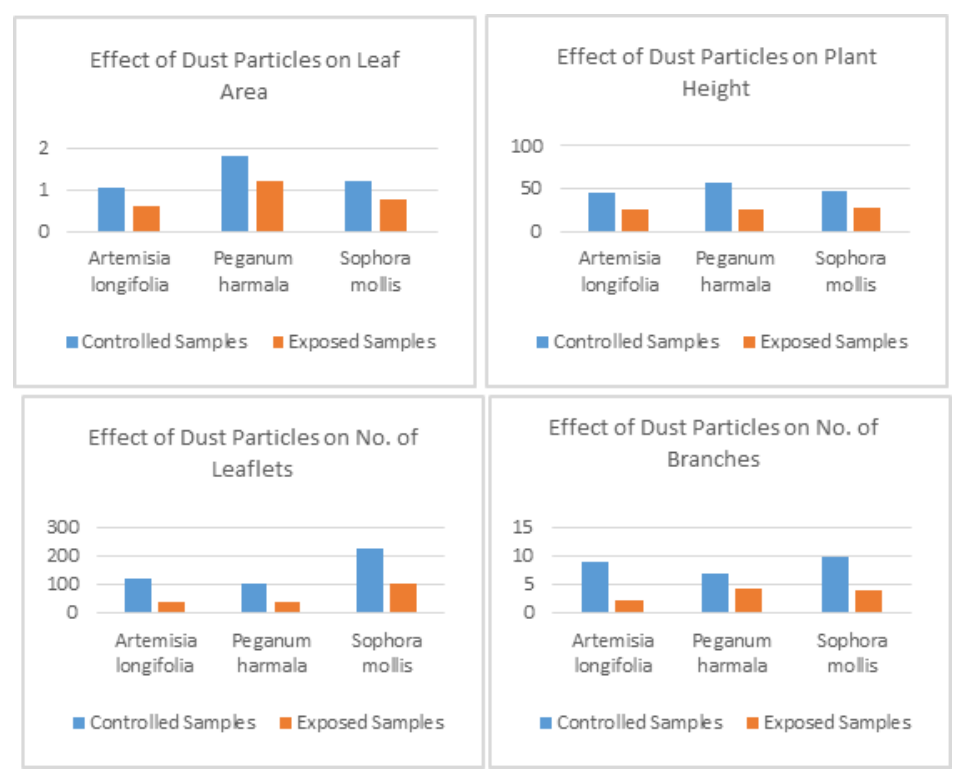

Figure 5. Graphs 5(a), 5(b), 5(c) and 5(d) the graphical presentation of effect of dust particles on different growth parameters of plants

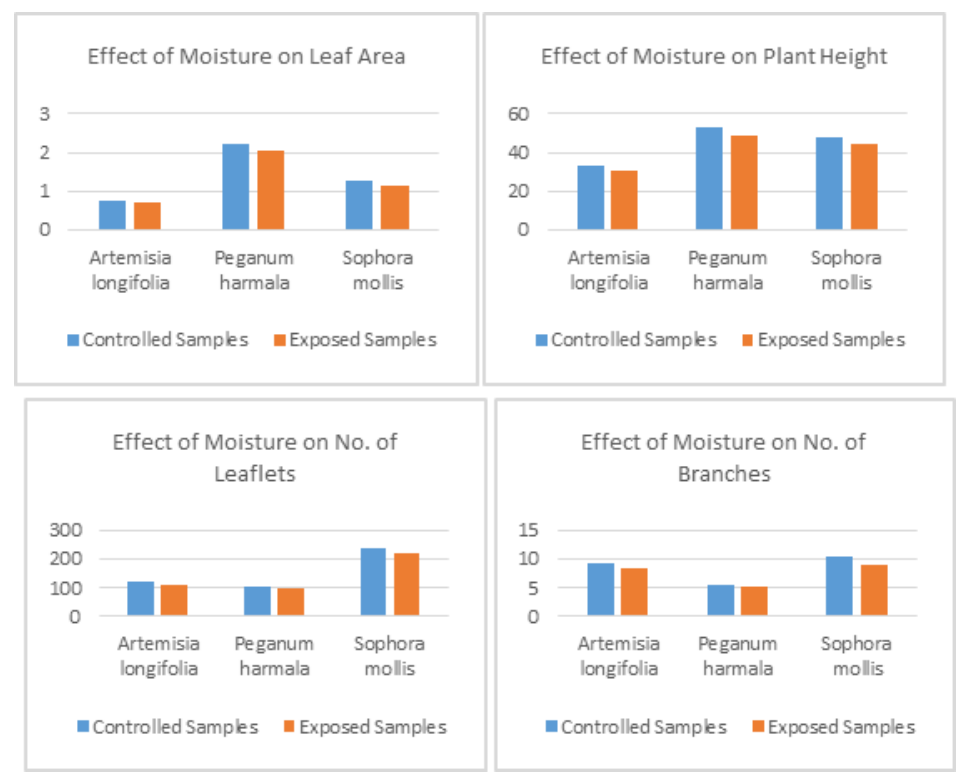

Figure 6. Graphs 6(a), 6(b), 6(c) and 6(d) the graphical presentation of effect of moisture on different growth parameters of plants

\section{Effect of sunlight on plant growth parameters}

In aggregate, sunlight did not find to have imparted a significant effect on growth parameters, however, the effect varied among the plant species. Samples of Artemisia longifolia showed significantly lesser values of all parameters as compared to other species, while in samples of sophora mollis, difference was in the same pattern but very least noteworthy (Figure 7).

Bergqvist et al. [21] also reported sunlight exposure to be having effect on berry plant while comparing its exposure to direct sunlight. Powles and Critchley [22] reported maximum leaf weight in plants exposed to 
sunlight. Results of current study also comply with the findings of Adamski et al., who have worked on the effect of $\mathrm{pH}$ and temperature on production of cylindrospermopsin in cyanobacteria.

\section{Effect of Altitude on plant growth} parameters

To find the effect of altitude on plant growth, samples were collected from Khanozai (1950 Meter altitude) and Kan Mehterzai (2250 meters altitude). Curbing out the values from samples, it was revealed that number of leaflets reduced at an average of $11 \%$ in specimens of all three plants taken from 2250 altitude. Nevertheless, other factors showed insignificant variation along with mixed tendencies among the samples (Figure 8).

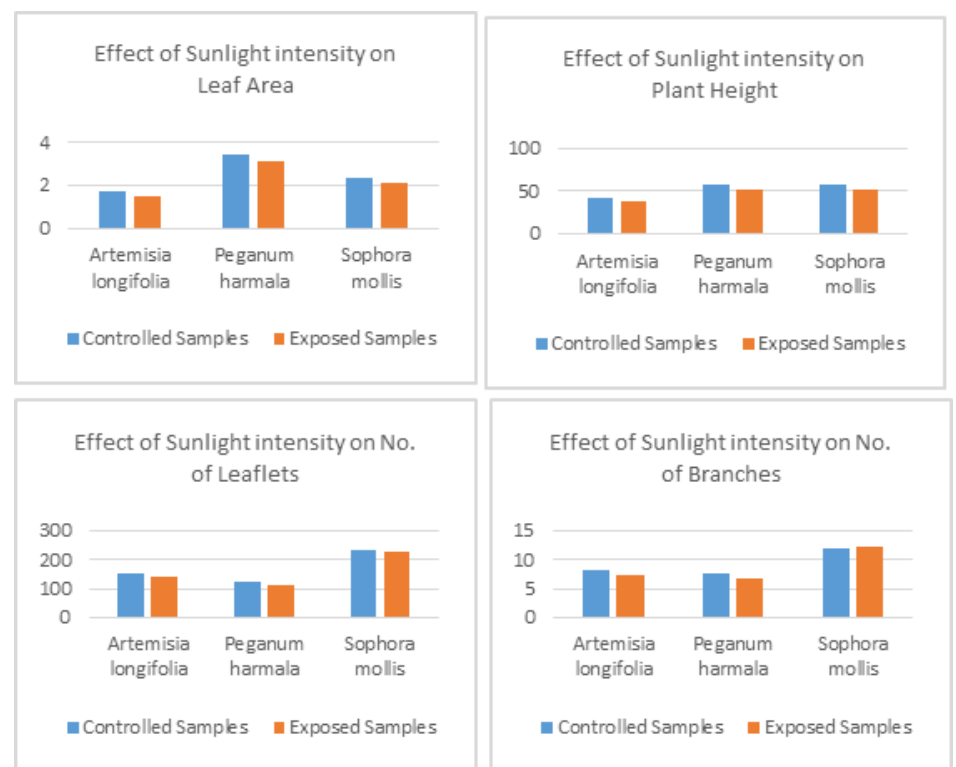

Figure 7. Graphs 7(a), 7(b), 7(c) and 7(d) the graphical presentation of effect of sunlight intensity on different growth parameters of plants

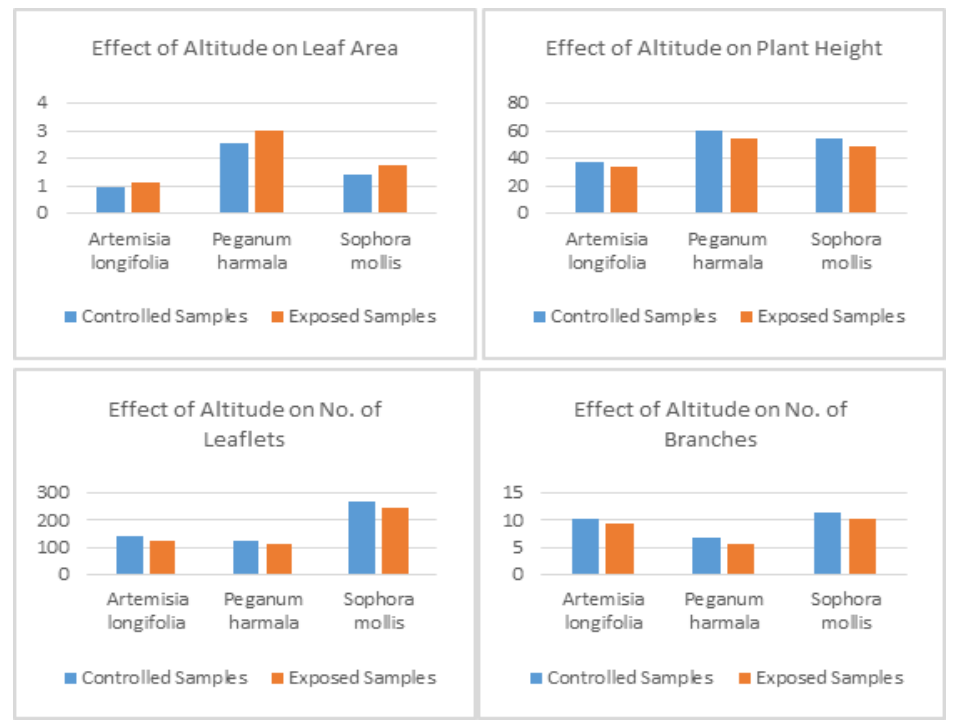

Figure 8. Graphs 8(a), 8(b), 8(c) and 8(d) the graphical presentation of effect of altitude on different growth parameters of plants 


\section{Conclusion}

As planned, a detailed list of plants has been developed through line intercept method which are found in the area and has been tabulated in above pages for reference. The same list is recommended for the students of Phytosociology to further elaborate through a deep and focused study. Results of impact study revealed that several factors impart negative impact on the growth of plants in which, for instance, dust found to be most deadly. This dust is released from chromite refineries established near Muslimbagh town and cause an average of 50 to $60 \%$ decrease in growth attributes of all samples recorded in this study. Based on this study, it is strongly recommended that chromite refineries may be transferred away from the human settlements and cultivated lands of Muslimbagh town and an Environment Impact Assessment (EIA) may be conducted for each of these refineries before establishing. Besides, Smoke from automobile also imparted some effect on plant growth but not in significant way. The highway passes in area leads to Punjab and Khyber Pakhtunkhwa provinces and connects Balochistan with these two provinces. Being part of the western route of CPEC, a boost in traffic flow is expected in near future which may turn the insignificant effect of automobile smoke into significant and thus some crucial steps are much needed and recommended to district authorities. These steps may include feasibility test of vehicles passing the road on continuous basis and plantation of trees by road side so that least smoke is emitted etc. Keeping in view the current wave of drought due to less rains, it is highly recommended that rotational grazing practice may be introduced so that livestock may get healthy and enough fodder for grazing. Plant samples of Artemisia and Peganum collected from human defecation points showed lesser growth values as compared to Sophora samples, which got positively affected from faeces. Government needs to discourage human defecation and construct public latrines in towns and sensitize the masses to construct household latrines in every house in rural areas.

\section{Authors' contributions}

Conceived and designed the experiments: MK Panizai \& SR Kakar, Performed the experiments: MK Panizai, Analyzed the data: KK Panizai, Contributed materials/ analysis/ tools: SR Kakar, Wrote the paper: MK Panizai.

\section{References}

1. Akhter R \& Mirza SN (2006). Arid steppes of Balochistan (Pakistan). Sci et Changements

Planétaires/Sécheresse 17(1): 203-209.

2. Government of Balochistan, UNICEF (2011). District Development Profile 2011 (Pishin) (PDF) (Report), pp 3. Retrieved 9 October 2016.

3. Sarwar A (2008). Droughts in Pakistan - a socio-political perspective. In: Jairath J, Ballabh V (eds) Droughts and integrated water resource management in South Asia: issues, alternatives and futures. SAGE Publications, New Delhi, pp 200-230.

4. Canfield RH (1941). Application of the line interception method in sampling range vegetation. $J$ of Forestry 39(4): 388-394.

5. Nasir E, Ali SI \& Stewart RR (1972). Flora of West Pakistan.

6. Fake C (2015). Soil Analysis, Placer and Nevada Counties, Publication Number 31-074C.

7. Hurley MJ, Gottuk DT, Hall Jr JR, Harada, K, Kuligowski ED, Puchovsky M \& Wieczorek CJ (Eds.) (2015). SFPE handbook of fire protection engineering. Springer.

8. Chaudhary P, Godara S, Cheeran AN \& Chaudhari AK (2012). Fast and accurate method for leaf area measurement. Inter $J$ of Computer Appl 49(9): 22-25. 
9. Nawazish S, Hussain M, Ashraf M, Ashraf MY \& Jamil A (2012). Effect of automobile related metal pollution $(\mathrm{Pb} 2+$ and $\mathrm{Cd} 2+)$ on some physiological attributes of wild plants. Intewr J of Agri and Biol 14(6).

10. Sridhar BM, Diehl SV, Han FX, Monts DL \& Su Y (2005). Anatomical changes due to uptake and accumulation of $\mathrm{Zn}$ and $\mathrm{Cd}$ in Indian mustard (Brassica juncea). Environ and Experi Bot 54(2): 131-141.

11. Doğanlar ZB \& Atmaca M (2011). Influence of airborne pollution on $\mathrm{Cd}$, $\mathrm{Zn}, \mathrm{Pb}, \mathrm{Cu}$, and $\mathrm{Al}$ accumulation and physiological parameters of plant leaves in Antakya (Turkey). Water Air \& Soil Pollution 214(1-4): 509-523.

12. Bhatti G \& Iqbai MZ (1988). Investigations into the effect of automobile exhausts on the phenology, periodicity and productivity of some roadside trees. Acta Societatis Botanicorum Poloniae 57(3): 395-399.

13. Munyati C \& Menwe O (2018). Effect of proximity to highways on soil chemical properties and grass condition at Mafikeng, South Africa. South African J of Plant and Soil 35(3): 231-234.

14. Na Y, Bao S, Hashimoto K, McCarthy C \& Hoshino B (2018). The effects of grazing systems on plant communities in steppe lands - a case study from Mongolia's pastoralists and inner mongolian settlement areas. Land 7(1): 10.

15. Craine JM \& Dybzinski R (2013). Mechanisms of plant competition for nutrients, water and light. Func Ecol 27(4): 833-840.

16. Meletiou-Christou MS, Banilas GP, Bardis C \& Rhizopoulou S (2011). Plant biomonitoring: impact of urban environment on seasonal dynamics of storage substances and chlorophylls of oleander. Global NEST J 13(4): 395404.

17. Iqbal, M. Z., \& Shafiq, M. (2000). Periodical effect of cement dust pollution on the growth of some plant species. Turk J of Bot 25(1): 19-24.

18. Tripathy BK, Mohanty RB \& Mishra N (2013). Effect of crusher dust on floristic composition and biological spectrum in tropical grassland of Odisha, India. $J$ of Ecol and The Nat Environ 5(6): 103-108.

19. Razmjoo KHORSHID, Heydarizadeh PARISA \& Sabzalian MR (2008). Effect of salinity and drought stresses on growth parameters and essential oil content of Matricaria chamomile. Inter $J$ Agric Biol 10(4): 451-454.

20. Ahmad,N \& Kanwar RS (1991). Effect of different moisture stress levels on corn growth in field lysimeters. Trans of the ASAE 34(5).

21. Bergqvist J, Dokoozlian N \& Ebisuda N (2001). Sunlight exposure and temperature effects on berry growth and composition of Cabernet Sauvignon and Grenache in the Central San Joaquin Valley of California. American J of Enol and Viticulture 52(1): 1-7.

22. Powles SB \& Critchley C (1980). Effect of light intensity during growth on photoinhibition of intact attached bean leaflets. Plant Physiol 65(6): 1181-1187. 